\title{
TWEAK/Fn14 system and crescent formation in IgA nephropathy
}

\author{
Yohei Sasaki, Yoshio Shimizu, Yusuke Suzuki, Satoshi Horikoshi and Yasuhiko Tomino*
}

\begin{abstract}
Background: The TNF-like weak inducer of apoptosis (TWEAK) contributes to kidney inflammation producing secretion by renal cells. The present study examined whether the level of TWEAK is associated with histologic findings in patients with IgA nephropathy (IgAN).

Methods: The levels of urinary TWEAK (UTWEAK) from 116 IgAN patients, 50 non-IgA kidney disease patients, and 50 healthy individuals were measured by ELISA. Histological findings of renal biopsy specimens of patients with IgAN were evaluated according to the Oxford classification and histological classification for IgAN in Japan. We investigated the expression of TWEAK/Fn14 in renal tissues of those patients and assessed the effect of TWEAK in glomerular mesangial cells and podocytes.
\end{abstract}

Results: The levels of UTWEAK in the patients with IgAN and other renal diseases were significantly higher than in the healthy controls $(P<0.001)$. In the IgAN patients, the levels of UTWEAK correlated significantly with urinary protein excretion and extracapillary proliferation $(r=0.54, P<0.001$ and $r=0.32, P<0.001$, respectively). In a comparison of the levels of UTWEAK at diagnosis with that of follow-up, the levels of UTWEAK in patients with clinical and partial remission decreased significantly. We showed not only increased expression of both TWEAK and Fn14 in IgAN patients with glomerular crescents but also TWEAK-induced cell motility in podocytes.

Conclusions: The relationship between the levels of UTWEAK and clinicopathological findings observed in this study suggests that TWEAK/Fn14 system affects crescent formation and proteinuria in patients with IgAN.

Keywords: TWEAK, IgA nephropathy, Crescent formation, Proteinuria

\section{Background}

The TNF-like weak inducer of apoptosis (TWEAK, TNFSF12), a TNF superfamily member, is synthesized as a type II transmembrane glycoprotein that circulates in plasma as a soluble form [1]. TWEAK is widely expressed in many cells and tissues including monocytes/macrophages, the heart, the brain, and kidneys [2]. The binding of TWEAK to its receptor, fibroblast growth factor-inducible-Fn14 (Fn14) [3,4], regulates cellular proliferation, differentiation, migration, inflammation, and apoptosis [5]. The plasma levels of soluble TWEAK have been reported to be associated with the aggravation of the endothelial function and mortality risk [6,7]. Recent studies have further indicated that the levels of urinary TWEAK (UTWEAK) correlated

\footnotetext{
* Correspondence: yasu@juntendo.ac.jp

Division of Nephrology, Department of Internal Medicine, Juntendo

University Faculty of Medicine, 2-1-1, Hongo, Bunkyo-ku, Tokyo 113-8421, Japan
}

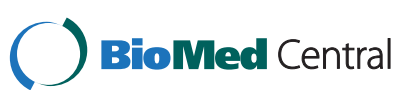

positively with lupus nephritis activity [8,9]. These findings suggest that TWEAK expression may reflect kidney inflammation and is associated with chronic kidney disease (CKD).

IgA nephropathy (IgAN) is the most common form of primary glomerulonephritis worldwide [10] and is one of the leading causes of end-stage renal disease (ESRD) [11]. The histologic features of IgAN show an increase in mesangial proliferation with matrix expansion; other glomerular lesions may include focal necrosis, segmental sclerosis, and crescent formations [12]. Podocyte injury is a common denominator in many forms of human glomerular diseases [13] and is characteristic of proteinuric kidney diseases, including IgAN [14]. Notably, podocyte loss from the glomerular basement membrane (GBM) in IgAN may cause the progression of proteinuria and glomerulosclerosis $[15,16]$. 
Previously, Fn14 expression was observed in tubular cells, glomerular mesangial cells, and podocytes $[17,18]$. TWEAK induces the expression of inflammatory cytokines, such as monocyte chemoattractant protein-1 (MCP-1), interleukin (IL)-6, RANTES, and CXCL16, and downregulates the expression of Klotho [19-22]. Therefore, TWEAK has proinflammatory effects on glomerular mesangial cells and podocytes [18,23], suggesting the pathological roles of the TWEAK/Fn14 system in the pathogenesis of glomerular injury. However, it is unknown how TWEAK contributes to the pathogenesis of IgAN. In the present study, we examined whether the levels of TWEAK are associated with histological findings and disease activity in patients with IgAN. In addition, we investigated the expression of TWEAK/ Fn14 in the renal tissues of those patients and assessed the effect of TWEAK in glomerular mesangial cells and podocytes.

\section{Methods}

\section{Patients and controls}

This study included patients who had undergone renal biopsy in the Juntendo University Hospital, Tokyo, Japan, from January 2005 to March 2011. Although we recruited 236 patients with biopsy-proven IgAN during this period, 96 patients were not included because urine samples were not obtained or there was poor conservation of pathologic materials. Of the remaining 140 patients, 15 had insufficient clinical data and thus were excluded. Nine of the remaining 125 renal biopsy samples contained less than 8 glomeruli, and thus were excluded according to the Oxford classification $[24,25]$. In the end, 116 patients with IgAN were included in this study.

We enrolled 50 patients with non-IgAN kidney diseases, including 12 patients with minimal change disease (MCD), 12 patients with membranous nephropathy $(\mathrm{MN}), 18$ patients with lupus nephritis (LN), and 8 patients with focal segmental glomerulosclerosis (FSGS) as disease controls. We also recruited 50 healthy subjects to serve as healthy controls.

Of the 116 patients with IgAN, 37 patients had follow-up data. They received steroid therapy $(n=8)$ or both steroid therapy and tonsillectomy $(n=29)$. The steroid therapy regimen consists of $0.5 \mathrm{~g} / \mathrm{day}$ of methylprednisolone for 3 days, three times every 2 months, and patients were given oral prednisolone (0.5 $\mathrm{mg} / \mathrm{kg}$ body weight) on alternate days for 6 months. The evaluation of therapeutic response of the IgAN patients was defined as follows [26]: clinical remission (CR, proteinuria $<0.3 \mathrm{~g} / \mathrm{gCr}$ with urinary sediment $\mathrm{RBC}<5$ / HPF), partial remission ( $\mathrm{PR}$, proteinuria $<0.3 \mathrm{~g} /$ gCr or urinary sediment $\mathrm{RBC}<5$ /HPF).
This study was conducted according to the Declaration of Helsinki and was approved by Institutional Review Board of Juntendo University Hospital. Informed consent was obtained from all patients and healthy subjects.

\section{Sample collection}

At the time of renal biopsy, all patients provided blood and freshly voided urine samples. The sera and supernatant from urine were separated by centrifugation, and were then stored in aliquots at $-80^{\circ} \mathrm{C}$ prior to measurement. Urine samples from the 37 patients with followup were also collected and stored.

\section{Measurement of human serum and urinary TWEAK}

The levels of serum TWEAK (sTWEAK) and UTWEAK were determined in duplicate with commercially available enzyme-linked immunosorbent assay (ELISA) kits (R\&D Systems, Minneapolis, MN), following the manufacturer's protocol. TWEAK assays were performed blindly, without knowledge of the patients' disease status or activity.

\section{Measurement of other markers}

Serum and urine measures from patients were determined in the clinical laboratory center in the Juntendo University Hospital. Levels of urinary protein excretion and uTWEAK were individually normalized to urinary creatinine levels. The estimated glomerular filtration rate (eGFR) was calculated using the Japanese eGFR equation [27].

\section{Pathologic analysis}

All renal biopsy specimens were evaluated with immunofluorescence, light-, and electron microscopy. For light microscopy, paraffin sections were stained with hematoxylin-eosin (HE), periodic acid-Schiff (PAS), and periodic acid methenamine silver-Masson trichrome (PAM-MT). The Oxford classification was used to evaluate histologic findings of renal biopsy specimens of IgAN patients [24,25]. We also evaluated renal biopsy sections using the histological classification for IgAN in Japan [28], of which the prognosis classification is as follows: global sclerosis, segmental sclerosis, or cellular/fibrocellular/fibrous crescent were observed in $<25 \%$ (Grade I), 25-49\% (Grade II), 50-74\% (Grade III) and $\geq 75 \%$ (Grade IV) of all glomeruli. The percentage of glomeruli with each glomerular lesion was analyzed. The histologic findings of each slide were evaluated by two nephrologists who did not know the details of the patients' clinical data. 


\section{Immunohistochemistry}

Renal biopsies were performed according to the clinical needs of the patients in the Juntendo University Hospital. Immunohistochemistry was performed on formalin-fixed paraffin-embedded tissue sections. Briefly, sections (3 $\mu \mathrm{m}$ thick) were autoclaved at $121^{\circ} \mathrm{C}$ for 10 minutes in a $0.01 \mathrm{M}$ citrate buffer ( $\mathrm{pH}$ 6.0). To block endogenous biotin, the slides were treated with an avidin/biotin blocking kit (Vector Laboratories, Burlingame, CA) and treated with $0.3 \% \mathrm{H}_{2} \mathrm{O}_{2}$ in methanol to inhibit endogenous peroxidase activity. The sections were visualized with first antibody for polyclonal goat anti-human TWEAK antibody (pAb) (R\&D Systems), rabbit anti-human Fn14 pAb (Bioworld Technology, St. Louis Park, MN), or isotypematched control IgG, and biotin-conjugated rabbit anti-goat IgG (DAKO, Carpinteria, CA) or goat antirabbit IgG (DAKO) by using avidin/biotin-peroxidase method.

\section{Cell culture}

Conditionally immortalized mouse podocytes were kindly provided by Dr. K. Asanuma (Kyoto University, Kyoto, Japan) and Dr. P. Mundel (Massachusetts General Hospital, Boston, USA) and were cultured as previously described $[29,30]$. Podocytes were maintained in an RPMI 1640 medium (Sigma, Tokyo, Japan) supplemented with 10\% FBS, penicillin/streptomycin (Life Technologies, CA), and $10 \mathrm{U} / \mathrm{ml}$ interferon- $\gamma$ at $33^{\circ} \mathrm{C}$. Podocytes were incubated at $37^{\circ} \mathrm{C}$ for $10-14$ days to differentiate without interferon- $\gamma$.

Mouse mesangial cells (MMC, SV 40 MES-13) were obtained from the American Type Culture Collection (Manassas, Va). The cells were grown at $37^{\circ} \mathrm{C}$ in a $3: 1$ mixture of Dulbecco's Modified Eagle's and Ham's F12 media (Sigma) supplemented with 5\% FBS, and penicillin/streptomycin.

\section{Cell proliferation assay}

MMC $\left(5 \times 10^{3}\right.$ cells per well $)$ were seeded in 96-well plates in duplicate with medium containing $0.1 \%$ FBS. Recombinant mouse TWEAK (R\&D Systems) at 0$1000 \mathrm{ng} / \mathrm{ml}$ was added at the beginning of the experiment. After stimulation of MMC with TWEAK for 24 hours, cell proliferation ELISA using BrdU was performed with a colorimetric immunoassay kit (Roche Diagnostics, Mannheim, Germany) following the manufacturer's instructions.

\section{Cytokine detection}

The concentration of MCP-1 in supernatants of MMC culture was examined by a mouse MCP-1 ELISA kit (R\&D Systems) according to the manufacturer's instructions. Recombinant mouse TWEAK was used at 0,10 , and $100 \mathrm{ng} / \mathrm{ml}$, for $3,6,12$, and 24 hours.

\section{Wound healing assay}

Wound healing assays were conducted as reported previously [30,31]. Differentiated wild-type podocytes $\left(5 \times 10^{5}\right)$ were seeded overnight in six-well plates. Monolayers were scratched with a $200 \mu$ l pipette tip, washed with PBS and added to fresh medium with TWEAK (0-1000 ng/ml). The monolayers were photographed using a grid as a marker, and the wound width $(\mu \mathrm{m})$ was measured at 0,12 and 24 hours using BZ-II Measurement Module (Keyence, Osaka, Japan) with BZ Viewer $^{\mathrm{Tm}}$ (Keyence). Migratory rates were calculated as $(\mathrm{A}-\mathrm{B}) / \mathrm{A} \times 100 \%$ or $(\mathrm{A}-\mathrm{C}) / \mathrm{A} \times 100 \%$, with $\mathrm{A}, \mathrm{B}$, and $\mathrm{C}$ reflecting the width of the wound at 0,12 , or 24 hours, respectively.

\section{Statistical analyses}

Data were expressed as proportions, mean $\pm \mathrm{SD}$, or median (interquartile range [IQR]) as appropriate. Categorical variables were compared using the $\chi^{2}$ test. Continuous variables were compared using unpaired $t$ test or Mann-Whitney $U$ test as appropriate. We evaluated the differences in each biochemical parameter among the glomerular diseases by a one-way analysis of variance (ANOVA) followed by a multiple comparison analyses. Each multiple comparison analysis was performed with Tukey's HSD (honest significance difference) mean separation test (parametric) or a Steel-Dwass test (nonparametric). Correlate variables were evaluated using Spearman's rank correlation coefficient test. Statistical analyses were performed using JMP 9.0 statistical software (SAS Institute, Cary, NC) and GraphPad Prism version 6.0 software (GraphPad Software, San Diego, CA). A $P$ value $<0.05$ was considered significant.

\section{Results}

\section{Demographic and clinical characteristics of patients with} IgAN and controls

The demographic and clinical characteristics of the IgAN patients and controls are summarized in Table 1. The mean age of the IgAN patients at diagnosis was $34.0 \pm 10.9$ years (range, $15-65$ years). The MCD patients, the MN patients, and the LN patients excreted significantly more urinary protein than IgAN patients. The levels of uTWEAK in the IgAN patients (median: 94.3, IQR 65.1-147.1 pg/mgCr) did not differ from any other disease groups. In our cohort, however, the levels of UTWEAK in the patients with IgAN, LN, MN, FSGS, and MCD were significantly higher than in the healthy controls $(P<0.001, P=0.001, P<0.001, P=0.005$, and $P=0.001$, respectively).

The levels of uTWEAK were significantly correlated with urinary protein levels in $\operatorname{IgAN}$ patients $(\mathrm{r}=0.54$, $P<0.001$, Figure $1 \mathrm{~A})$, in $\mathrm{MN}$ patients $(\mathrm{r}=0.77, P=0.003)$, 
Table 1 Demographic and clinical characteristics of IgAN patients, disease controls, and healthy controls

\begin{tabular}{|c|c|c|c|c|c|c|c|}
\hline \multirow[t]{2}{*}{ Characteristics } & \multirow{2}{*}{$\begin{array}{l}\operatorname{IgAN} \\
(n=116)\end{array}$} & \multirow{2}{*}{$\begin{array}{l}\text { LN } \\
(n=18)\end{array}$} & \multirow{2}{*}{$\begin{array}{l}\text { MN } \\
(n=12)\end{array}$} & \multirow{2}{*}{$\begin{array}{l}\text { FSGS } \\
(n=8)\end{array}$} & \multirow{2}{*}{$\begin{array}{l}\text { MCD } \\
(n=12)\end{array}$} & \multirow{2}{*}{$\begin{array}{l}\text { Healthy } \\
\text { controls } \\
(n=50)\end{array}$} & \multirow[t]{2}{*}{$\begin{array}{l}P \\
\text { value }\end{array}$} \\
\hline & & & & & & & \\
\hline Age (years) & $34.0 \pm 10.9$ & $33.0 \pm 9.9$ & $55.7 \pm 9.5^{A-E}$ & $35.9 \pm 13.1$ & $31.8 \pm 19.3$ & $33.6 \pm 5.5$ & $<0.001$ \\
\hline Men, $n(\%)$ & $53(45.7)$ & $2(11.1)$ & $9(75.0)$ & $5(62.5)$ & $6(50.0)$ & $32(64.0)$ & 0.002 \\
\hline $\mathrm{BMI}\left(\mathrm{kg} / \mathrm{m}^{2}\right)$ & $21.7 \pm 3.0$ & $21.7 \pm 4.5$ & $23.5 \pm 2.5$ & $24.3 \pm 5.3$ & $23.3 \pm 3.8$ & $22.0 \pm 2.0$ & 0.08 \\
\hline $\begin{array}{l}\text { Mean arterial pressure } \\
(\mathrm{mmHg})\end{array}$ & $83.8 \pm 13.8$ & $82.4 \pm 16.3$ & $87.3 \pm 8.9$ & $85.8 \pm 10.1$ & $79.1 \pm 8.1$ & $86.0 \pm 11.0$ & 0.62 \\
\hline $\begin{array}{l}\text { eGFR }(\mathrm{ml} / \mathrm{min} \text { per } \\
\left.1.73 \mathrm{~m}^{2}\right)\end{array}$ & $81.9 \pm 29.0$ & $82.8 \pm 32.6$ & $79.3 \pm 29.4$ & $76.8 \pm 28.3$ & $95.7 \pm 23.7$ & N/A & 0.56 \\
\hline $\begin{array}{l}\text { CKD Stages 1/2/3/4/5 } \\
\left(\text { KDOQI) }(\%)^{\mathrm{a}}\right.\end{array}$ & $32 / 47 / 20 / 1 / 0$ & $44 / 39 / 11 / 0 / 6$ & $25 / 50 / 25 / 0 / 0$ & $38 / 50 / 0 / 13 / 0$ & $50 / 42 / 8 / 0 / 0$ & - & 0.13 \\
\hline $\begin{array}{l}\text { Urinary protein } \\
\text { excretion }(\mathrm{g} / \mathrm{gCr})\end{array}$ & $0.61 \pm 0.88$ & $2.22 \pm 2.62^{F}$ & $3.76 \pm 2.97^{G}$ & $1.70 \pm 1.91$ & $5.46 \pm 4.35^{\mathrm{H}, \mathrm{I}, \mathrm{J}}$ & N/A & $<0.001$ \\
\hline $\begin{array}{l}\text { uTWEAK (pg/mgCr, } \\
\text { median, IQR) }\end{array}$ & $94.3(65.1,147.1)^{\mathrm{K}}$ & $130.8(70.2,163.8)^{\mathrm{L}}$ & $151.9(98.8,285.1)^{\mathrm{M}}$ & $168.9(107.8,304.7)^{\mathrm{N}}$ & $180.6(92.8,331.8)^{\mathrm{O}}$ & $64.2(32.2,84.9)$ & $<0.001$ \\
\hline
\end{tabular}

Abbreviations: BMI, body mass index; eGFR, estimated glomerular filtration rate; UTWEAK, urinary TWEAK; IQR, interquartile range; IgAN, IgA nephropathy; LN, lupus nephritis; MN, membranous nephropathy; FSGS, focal segmental glomerulosclerosis; MCD, minimal change disease; NA, not available; ANOVA, analysis of variance; HSD, honest significant difference.

${ }^{a}$ CKD stage $1,2,3,4$, and 5 were divided by eGFR $\geq 90,60-89,30-59,15-29$, and $<15$, respectively

Data are expressed as proportions, mean $\pm \mathrm{SD}$, or median (interquartile range [IQR]) as appropriate. Differences among the groups were analyzed by a one-way ANOVA. The multiple comparisons for age, BMI, mean arterial pressure, eGFR, and urinary protein excretion were performed by Tukey's HSD mean separation tests. A nonparametric SteelDwass test was used for UTWEAK. Differences between the disease groups in gender and CKD stages were determined by $X^{2}$ tests. A: $P<0.001$ vs. IgAN; B: $P<0.001$ vs. LN; C: $P<0.001$ vs. FSGS; D: $P<0.001$ vs. MCD; E: $P<0.001$ vs. healthy controls; $\mathrm{F}: P=0.001$ vs. IgAN; G: $P<0.001$ vs. IgAN; H: $P<0.001$ vs. IgAN; $: P<0.001$ vs. LN; J: $P<0.001$ vs. FSGS; K: $P<0.001$ vs. healthy controls; L: $P=0.001$ vs. healthy controls; $\mathrm{M}: P<0.001$ vs. healthy controls; $\mathrm{N}: P=0.005$ vs. healthy controls; $\mathrm{O}: P=0.001$ vs. healthy controls.

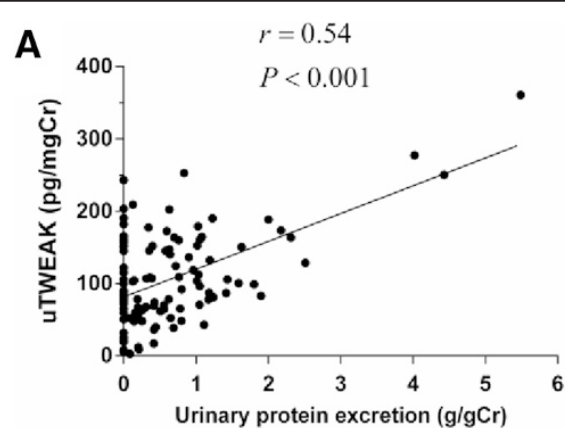

C

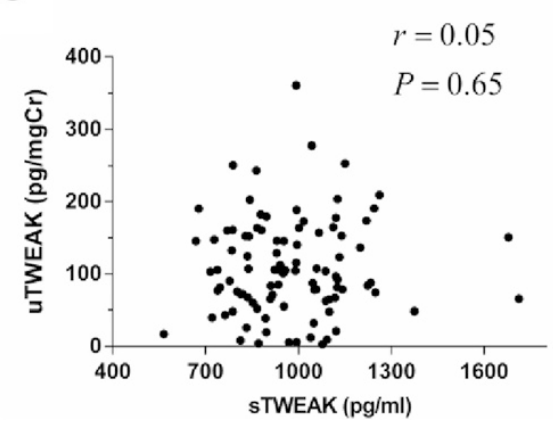

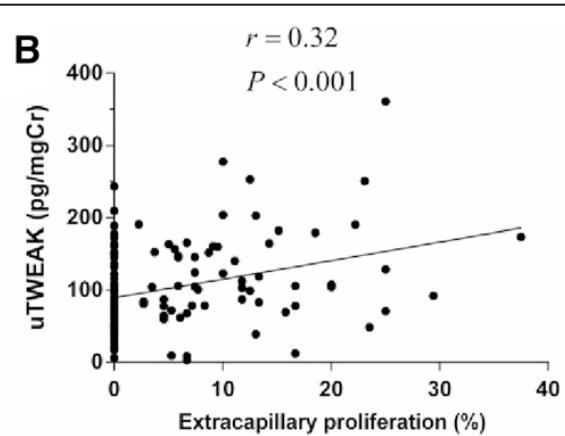

D

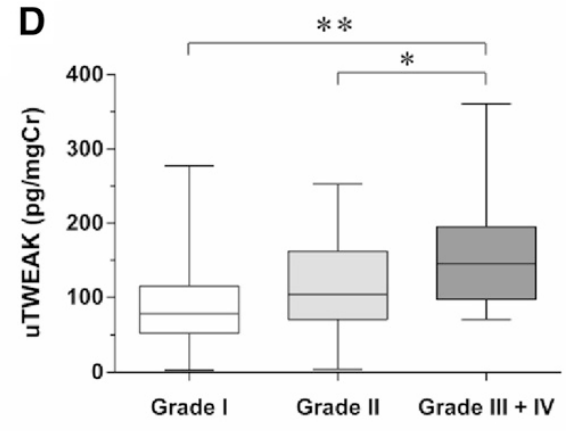

Figure 1 Relationship between the levels of UTWEAK and clinical and histopathologic characteristics in patients with IgAN. The levels UTWEAK at the time of renal biopsy in 116 IgAN patients showed significantly correlations with: (A) urinary protein excretion, $r=0.54, P<0.001$; and (B) extracapillary proliferation, $r=0.32, P<0.001$. (C) There was no significant association between the levels of serum TWEAK (sTWEAK) and uTWEAK ( $r=0.05, P=0.65$ ). (D) Box plots of the levels of UTWEAK with different histological grades in patients with IgAN. The level of UTWEAK in Grade III + IV ( $n=12$, median: 145.7, IQR 97.5-195.6 pg/mgCr) was significantly higher than those in Grade I ( $n=63$, median: 78.6, IQR 52.3-115.7 pg/mgCr; $\left.{ }^{* *} P<0.001\right)$ or Grade II ( $n=41$, median: 103.7, IQR 70.9-162.5 pg/mgCr; $\left.{ }^{*} P<0.05\right)$. The lines in the box plots and the error bars are median and 10-90 percentiles. 
and in MCD patients $(\mathrm{r}=0.76, P=0.004)$. No correlation was detected between the levels of UTWEAK and urinary protein excretion in $\mathrm{LN}$ patients $(\mathrm{r}=0.17, P=0.51)$ and FSGS patients $(r=0.20, P=0.65)$. There was a significant correlation between the levels of uTWEAK and the extracapillary proliferation in IgAN patients (Figure 1B).

\section{Clinical and histopathologic characteristics in subgroups of IgAN patients}

The IgAN patients were next divided into three equal groups according to the tertiles of the UTWEAK distribution: Group 1, uTWEAK levels $<72.3 \mathrm{pg} / \mathrm{mgCr}$; Group 2, uTWEAK levels between 72.3 and $123.0 \mathrm{pg} / \mathrm{mgCr}$; and Group 3, uTWEAK levels $>123.0 \mathrm{pg} / \mathrm{mgCr}$ (Table 2).
The urinary protein excretion, degree of interstitial fibrosis and extracapillary proliferation in the IgAN patients of Group 3 were significantly higher than the IgAN patients of Group $1(P<0.001, P=0.009$, and $P=0.02$, respectively). Among the cases, we observed no significant association between the levels of serum TWEAK (sTWEAK) and the clinical and histological parameters, including uTWEAK (Figure 1C).

\section{Association of UTWEAK levels with histologic characteristics}

The distribution by histological Grades I, II, III, and IV was $54.3,35.3,7.8$, and $2.6 \%$, respectively. The level of UTWEAK in Grade III + IV was significantly higher than

Table 2 Clinical and histopathologic characteristics in subgroups of IgAN patients defined by tertiles of uTWEAK

\begin{tabular}{|c|c|c|c|c|}
\hline \multirow[t]{3}{*}{ Characteristics } & $\operatorname{IgAN}$ Group $1(n=39)$ & $\lg A N$ Group $2(n=39)$ & $\operatorname{IgAN}$ Group $3(n=38)$ & \multirow{3}{*}{$\begin{array}{l}P \\
\text { value }\end{array}$} \\
\hline & $\mathrm{pg} / \mathrm{mgCr}$, median (IQR) & $\mathrm{pg} / \mathrm{mgCr}$, median (IQR) & $\mathrm{pg} / \mathrm{mgCr}$, median (IQR) & \\
\hline & $50.7(21.1,65.3)$ & $96.4(81.2,105.7)$ & $163.8(147.1,190.6)$ & \\
\hline \multicolumn{5}{|l|}{ Clinical } \\
\hline Age (years) & $33.2 \pm 10.2$ & $32.9 \pm 10.9$ & $36.1 \pm 11.6$ & 0.39 \\
\hline Men, $n(\%)$ & $16(41.0)$ & $25(64)$ & $12(32)$ & 0.01 \\
\hline $\mathrm{BMI}\left(\mathrm{kg} / \mathrm{m}^{2}\right)$ & $21.4 \pm 2.7$ & $22.4 \pm 2.9$ & $21.4 \pm 3.3$ & 0.22 \\
\hline Mean arterial pressure $(\mathrm{mmHg})$ & $82.8 \pm 11.2$ & $84.1 \pm 19.2$ & $84.6 \pm 9.5$ & 0.84 \\
\hline eGFR (ml/min per $\left.1.73 \mathrm{~m}^{2}\right)$ & $83.3 \pm 25.8$ & $82.4 \pm 35.2$ & $80.0 \pm 25.8$ & 0.88 \\
\hline \multicolumn{5}{|l|}{ CKD Stages 1, 2, 3, and 4 (KDOQI) (\%) } \\
\hline Stage 1: >90 & $15(38.5)$ & $9(23.7)$ & $13(34.2)$ & \multirow[t]{4}{*}{0.35} \\
\hline Stage 2: 60-89 & $16(41.0)$ & $23(60.5)$ & $15(39.5)$ & \\
\hline Stage 3: 30-59 & $7(17.9)$ & $6(15.8)$ & $10(26.3)$ & \\
\hline Stage 4: 15-29 & $1(2.6)$ & $0(0)$ & $0(0)$ & \\
\hline Urinary protein excretion $(\mathrm{g} / \mathrm{g} C \mathrm{r})$ & $0.28 \pm 0.30$ & $0.51 \pm 0.60$ & $1.03 \pm 1.28^{A, B}$ & $<0.001$ \\
\hline class $0:<0.30$ & $24(61.5)$ & $20(51.3)$ & $11(28.9)$ & \multirow[t]{4}{*}{0.004} \\
\hline class 1: 0.30-0.99 & $13(33.3)$ & $8(20.5)$ & $13(34.2)$ & \\
\hline class 2: 1.00-2.99 & $2(5.2)$ & $11(28.2)$ & $11(28.9)$ & \\
\hline class $3: \geq 3.00$ & $0(0)$ & $0(0)$ & $3(7.9)$ & \\
\hline sTWEAK (pg/ml, median, IQR) & $921.4(828.8,1089.1)$ & $957.1(874.3,1103.7)$ & $941.5(836.4,1124.6)$ & 0.95 \\
\hline \multicolumn{5}{|l|}{ Histopathologic mean \pm SD (range) } \\
\hline Total glomerular number & $18.2 \pm 7.9(8-42)$ & $19.6 \pm 7.5(8-37)$ & $18.7 \pm 8.0(8-44)$ & 0.74 \\
\hline Global glomerular sclerosis (\%) & $7.6 \pm 11.0(0-50.0)$ & $11.0 \pm 13.5(0-62.5)$ & $13.7 \pm 13.3(0-44.4)$ & 0.11 \\
\hline Mesangial hypercellularity score & $0.47 \pm 0.29(0.09-1.3)$ & $0.57 \pm 0.30(0.1-1.6)$ & $0.61 \pm 0.25(0.13-1.1)$ & 0.12 \\
\hline Endocapillary hypercellularity (\%) & $3.0 \pm 5.8(0-26.7)$ & $1.6 \pm 2.9(0-13.3)$ & $3.7 \pm 5.6(0-20.0)$ & 0.15 \\
\hline Segmental glomerulosclerosis (\%) & $4.0 \pm 8.1(0-40.0)$ & $5.5 \pm 7.4(0-37.5)$ & $6.6 \pm 9.1(0-33.3)$ & 0.37 \\
\hline Interstitial fibrosis (\%) & $14.3 \pm 5.7(6.3-28.0)$ & $15.4 \pm 5.6(3.8-32.8)$ & $18.6 \pm 7.1(7.9-39.7)^{c}$ & 0.01 \\
\hline Extracapillary proliferation (\%) & $3.6 \pm 6.6(0-25.0)$ & $5.9 \pm 7.5(0-29.4)$ & $8.5 \pm 8.9(0-37.5)^{D}$ & 0.02 \\
\hline Histological-grade I/II/II/IV (\%) ${ }^{a}$ & $69 / 28 / 0 / 3$ & $59 / 33 / 8 / 0$ & $34 / 44 / 16 / 5$ & 0.03 \\
\hline
\end{tabular}

Abbreviations: BMI, body mass index; eGFR, estimated glomerular filtration rate; uTWEAK, urinary TWEAK; sTWEAK: serum TWEAK; IQR, interquartile range; ANOVA, analysis of variance; HSD, honest significant difference.

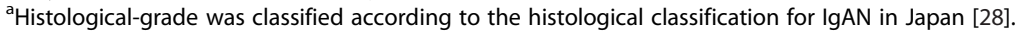

Differences among the groups were analyzed by a one-way ANOVA. The multiple comparisons for urinary protein excretion, interstitial fibrosis, and extracapillary proliferation were performed by Tukey's HSD mean separation tests. Categorical data were determined by $X^{2}$ tests. A: $P<0.001$ vs. Group $1 ; B$ : $P=0.02$ vs. Group 2 ; C: $P=0.009$ vs. Group 1; D: $P=0.02$ vs. Group 1. 
those in Grades I or II (Figure 1D). In the Oxford classification, the levels of uTWEAK in IgAN patients with M1, En1, S1, and T1, 2 were relatively higher than those with M0, En0, S0, and T0, although a significant difference was not detected (Table 3).

Both univariate and multivariate logistic analyses were performed to evaluate the impact of UTWEAK on the histologic lesions (Table 4). Interstitial fibrosis and extracapillary proliferation were statistically significant factors that were associated with the levels of uTWEAK. In a multivariate analysis, extracapillary proliferation was a significant independent factor that impacted the levels of uTWEAK.

The changes in the levels of UTWEAK at renal biopsy and during follow-up

During follow-up with a median duration of 36 (IQR 24-40) weeks, we obtained urine samples from $37 \mathrm{pa}$ tients with therapeutic responses. There were 12 patients achieving CR, 25 patients achieving PR, meaning that all patients responded to the treatment. At diagnosis the levels of UTWEAK in the patients with CR were significantly higher than those in PR $(P<0.05)$. In a comparison of the levels of uTWEAK at diagnosis with that of follow-up, the levels of UTWEAK in patients with CR and PR decreased significantly (Figure 2, A and B).

\section{Expression of TWEAK and Fn14 in renal biopsies from IgAN patients}

We investigated the localization of TWEAK in the renal biopsies from IgAN patients by immunohistochemistry. The expression of both TWEAK and Fn14 were increased in renal tubular cells in IgAN patients (Figure 3, A, B, D, and E). In the IgAN patients with glomerular crescents, TWEAK and Fn14 were detected in glomerular tufts and the crescents. In the controls (renal biopsies from patients

Table 3 Renal biopsy section evaluated with the Oxford classification (MEST)

\begin{tabular}{lllll}
\hline $\begin{array}{l}\text { Oxford } \\
\text { classification }\end{array}$ & $\begin{array}{l}\text { IgAN patients, } \\
\boldsymbol{n}(\%)\end{array}$ & $\begin{array}{l}\text { uTWEAK } \\
\text { (pg/mgCr, median, IQR) }\end{array}$ & $\begin{array}{l}\boldsymbol{P} \\
\text { value }^{\mathbf{a}}\end{array}$ \\
\hline M & 0 & $59(50.9)$ & $92.1(64.5,136.7)$ & 0.49 \\
& 1 & $57(49.1)$ & $96.4(66.6,154.8)$ & \\
E & 0 & $77(66.4)$ & $87.3(64.7,141.1)$ & 0.18 \\
& 1 & $39(33.6)$ & $106.0(67.8,160.1)$ & \\
S & 0 & $62(53.4)$ & $81.2(59.9,145.5)$ & 0.20 \\
& 1 & $54(46.6)$ & $103.5(73.3,151.2)$ & \\
T & 0 & $106(91.4)$ & $91.1(64.9,145.5)$ & 0.21 \\
& 1,2 & $10(8.6)$ & $150.9(63.9,184.7)$ & \\
\hline
\end{tabular}

Abbreviations: UTWEAK, urinary TWEAK Mesangial hypercellularity score of $\leq 0.5$ (M0) or $>0.5(\mathrm{M} 1)$, absence (E0) or presence (E1) of endocapillary hypercellularity, absence (SO) or presence (S1) of segmental glomerulosclerosis, and tubular atrophy/interstitial fibrosis of $0-25 \%$ (T0), 26-50\% (T1), and $>50 \%$ (T2). a Mann-Whitney $U$ test.
Table 4 Univariate and multivariate regression analyses of the pathologic factors that associate with UTWEAK in IgAN

\begin{tabular}{|c|c|c|c|c|}
\hline \multirow[t]{2}{*}{ Variable } & \multicolumn{2}{|c|}{$\begin{array}{l}\text { Univariate } \\
\text { analysis }\end{array}$} & \multicolumn{2}{|c|}{$\begin{array}{l}\text { Multivariate } \\
\text { analysis }\end{array}$} \\
\hline & $r$ & $P$ value & $t$ & $P$ value \\
\hline Global glomerular sclerosis (\%) & 0.20 & 0.03 & 1.28 & 0.20 \\
\hline Mesangial hypercellularity score & 0.14 & 0.13 & 0.27 & 0.79 \\
\hline Endocapillary hypercellularity (\%) & 0.18 & 0.05 & 1.49 & 0.14 \\
\hline Segmental glomerulosclerosis (\%) & 0.11 & 0.23 & 0.45 & 0.65 \\
\hline Interstitial fibrosis (\%) & 0.24 & 0.01 & 1.30 & 0.20 \\
\hline Extracapillary proliferation (\%) & 0.32 & $<0.001$ & 2.72 & 0.007 \\
\hline
\end{tabular}

with MCD), two images of the same glomeruli showed very slight staining for TWEAK and Fn14 in glomeruli, while intense staining was observed in renal tubular cells (Figure 3, $\mathrm{C}$ and F). TWEAK and Fn14 were also detected in the glomeruli of other crescentic glomerulonephritis (GN), including ANCA-associated renal vasculitis (data not shown).

\section{TWEAK regulates mesangial cell proliferation and} podocyte migration

To confirm whether TWEAK may affect the proliferation or apoptosis of kidney cells, we performed a cell proliferation assay. The proliferation of MMC was significantly increased under the stimulation of TWEAK $(10-1000 \mathrm{ng} / \mathrm{ml})$, with the highest effect at $1000 \mathrm{ng} / \mathrm{ml}$ (Figure 4A). We examined TWEAK-induced MCP-1 expression in MMC. Protein expression was increased in both the dose of TWEAK and time-dependent manners (Figure 4B).

Next, we analyzed whether TWEAK has a role in the motility of podocytes. In the wound healing assay, as compared with the control at 24 hours, TWEAK (100, $1000 \mathrm{ng} / \mathrm{ml}$ ) significantly enhanced cell motility in differentiated podocytes (Figure 4C).

\section{Discussion}

In the present study, we showed that the urine excretion of soluble TWEAK is associated with clinicopathological findings in patients with IgAN. Notably, we also demonstrated that TWEAK significantly enhanced cell motility in podocytes and in the proliferation of mesangial cells, known to be an important feature of the histopathology of IgAN. Mesangial cells and podocytes constitutively express TWEAK and Fn14 [18,23]. Most cases of proteinuria are associated with the effacement of podocyte foot processes, which represents podocyte dynamics in vivo or the motility of podocytes [13,30]. Podocytes stay attached to the GBM, but an altered cell motility of podocytes results in foot processes effacement and proteinuria. Since TWEAK enhanced podocyte motility, 
A

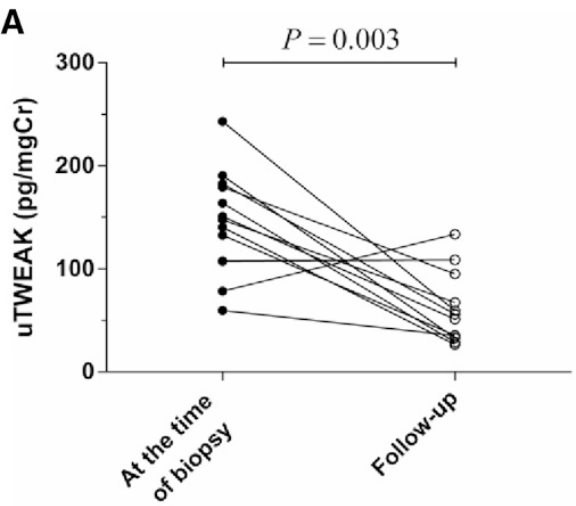

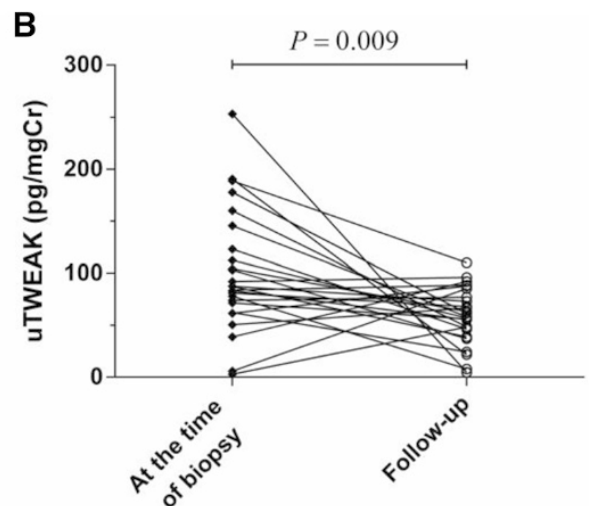

Figure 2 The changes in the levels of uTWEAK in patients with IgAN during follow-up. (A) Patients with clinical remission $(n=12)$ : the levels of UTWEAK at the time of biopsy (median: 149.2, IQR 113.8-181.8 pg/mgCr) decreased significantly compared with those of therapy-induced clinical remission (median: 53.8, IQR 33.6-88.5 pg/mgCr; $P=0.003$ ). (B) Patients with partial remission $(n=25)$ : the levels of uTWEAK at the time of biopsy (median: 87.3, IQR 67.1-134.3 pg/mgCr) also decreased compared with those of therapy-induced partial remission (median: 58.4, IQR 42.6-81.3 pg/mgCr; $P=0.009)$. Wilcoxon signed-rank test.

Fn14 activation in podocytes may associate with the development of proteinuria. In fact, we confirmed that the levels of UTWEAK were significantly correlated with urinary protein excretion not only in IgAN patients, but also in MCD and MN patients. However, no correlation was observed between the levels of UTWEAK and the degree of proteinuria in LN patients, as seen in a previous study [8]. Therefore, LN with proteinuria may be affected by additional other factors or mediators.
The underlying mechanisms as to why TWEAK relates to the development of proteinuria are unknown. However, experimental studies, using pharmacological or genetic approaches, have clearly shown that TWEAK activates Fn14 following renal inflammation [22,32]. TWEAK activates the canonical nuclear factor-kB (NF$\kappa B)$ pathway to induce the expression of both soluble and membrane-bound inflammatory chemokines, including MCP-1, RANTES and CXCL16 [18,20,23]. The

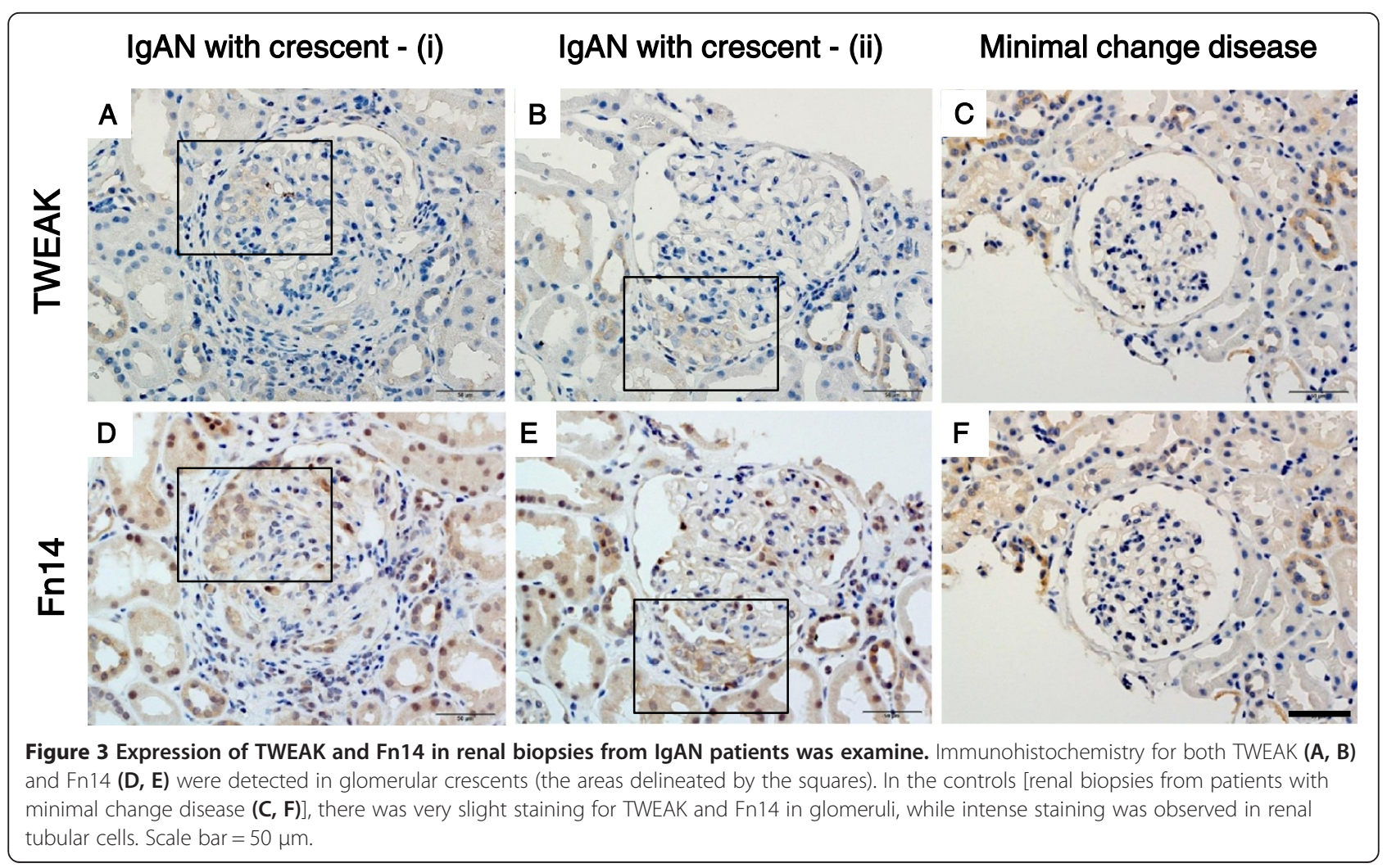



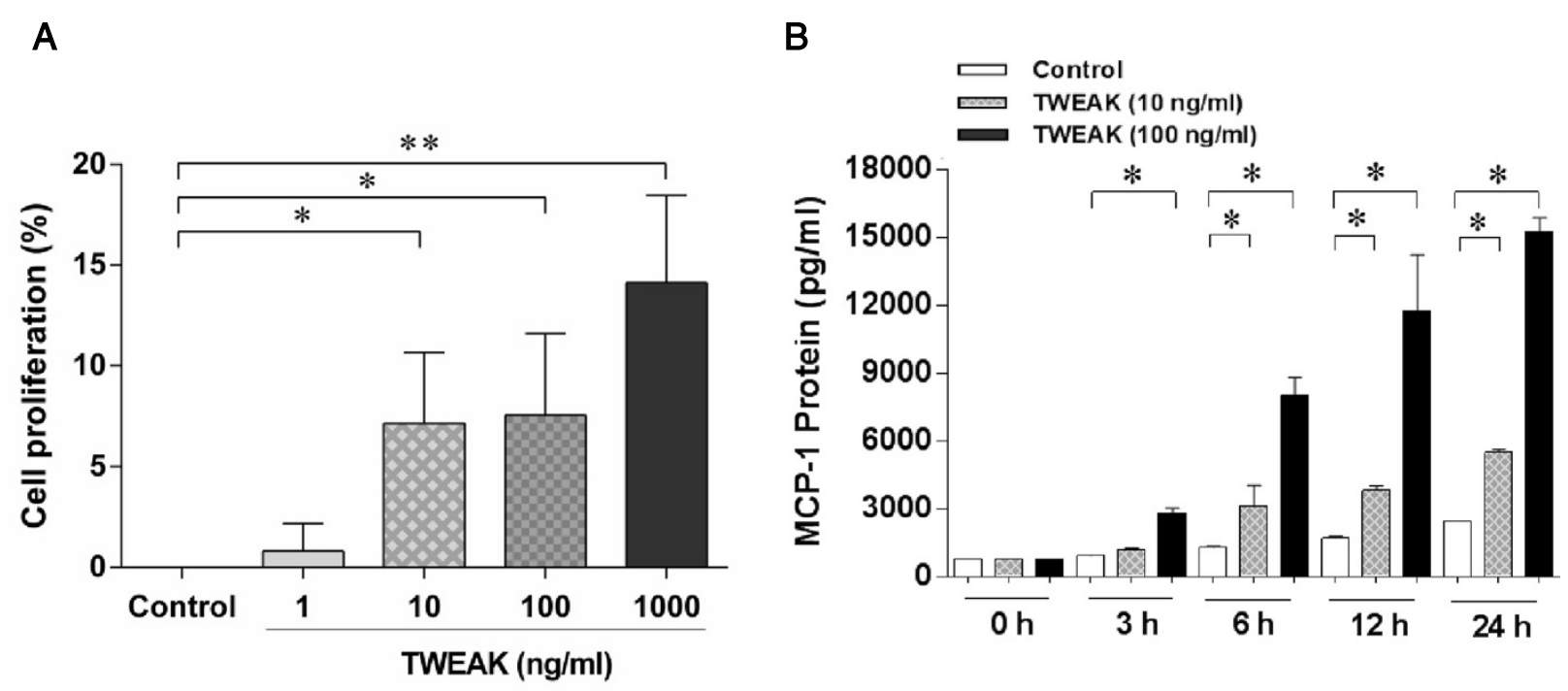

C

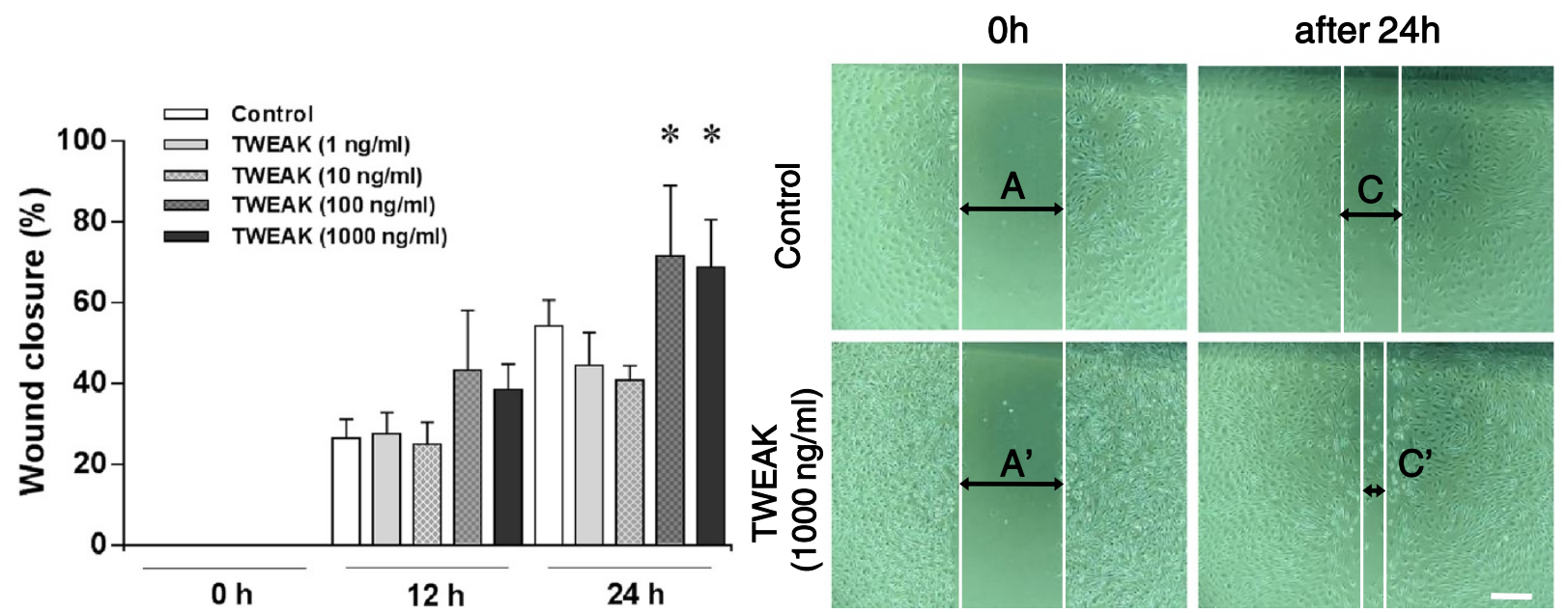

Figure 4 TWEAK actions on renal cells in vitro. (A) TWEAK modulates mesangial cells proliferation. The proliferation of MMC is significantly increased following stimulation with TWEAK (10-1000 $\mathrm{ng} / \mathrm{ml}$ ) for a 24-hour incubation. Data are expressed as mean \pm SD of five independent experiments. ${ }^{*} P<0.001$ vs. control; ${ }^{*} P<0.05$ vs. control. (B) MCP-1 secretion in response to TWEAK stimulation is dose and time dependent. MCP-1 protein levels in TWEAK stimulated MMC supernatants are shown. Data are expressed as mean \pm SD of three independent experiments. ${ }^{*} P<0.05$, TWEAK at $10,100 \mathrm{ng} / \mathrm{ml}$ vs. control. (C) TWEAK stimulates podocyte motility as evaluated by wound healing assay. After the scraping of the podocyte cell layer, cells have started to migrate into the wound track. The wound closures were significantly enhanced in the presence of TWEAK $(100,1000 \mathrm{ng} / \mathrm{ml})$ at 24 hours. Compared with the control, TWEAK enhanced directed cell migration in differentiated podocytes. Data are expressed as mean \pm SD of five independent experiments. ${ }^{*} P<0.05$, TWEAK at 100, $1000 \mathrm{ng} / \mathrm{ml}$ vs. control 24 hours. Scale bar $=200 \mu \mathrm{m}$.

present results showed that TWEAK modulates cell proliferation and MCP-1 production in glomerular mesangial cells in a dose-dependent manner. Recently, it has been demonstrated that TWEAK activates NF-kB and increases MCP-1 expression in podocytes [33]. Podocyte-derived MCP-1 could activate the cysteinecysteine chemokine receptor 2 (CCR2) in podocytes in a autocrine or paracrine manner. Furthermore, in podocytes MCP-1 has been reported to promote motility $[34,35]$, actin cytoskeleton rearrangement [35], and decreased nephrin expression [36]. Accordingly, these data may indirectly support our findings and suggest that the TWEAK/Fn14 pathway increases inflammatory settings and thus further enhances cell motility in podocytes leading to proteinuria.

The Oxford classification of IgAN identified pathological variables, the MEST score was associated closely with kidney failure, which was also validated in previous studies [37-40]. A recent study from Japan reported that a histological classification of IgAN could identify the risk of progression to ESRD [28]. Multivariate logistic analysis showed that the risk of progression to ESRD 
was higher in histological Grades II, III, and IV than in histological Grade I. Our results confirmed that the levels of UTWEAK increased in parallel with the Japanese histological grade. However, we did not detect any significant relationship between UTWEAK and each parameter in the Oxford classification. Extremely mild and severe cases were excluded in this classification [41]. It is possible that our study cohort consisted of populations that were lower in proteinuria and higher in eGFR as compared with that of other studies [37-39] as we could not detect differences in each histologic parameter.

In a multivariate analysis, we found that extracapillary proliferation was a significant independent factor that was associated with the levels of uTWEAK. To confirm whether these findings are relevant to pathophysiological conditions, we evaluated both TWEAK and Fn14 expression in renal biopsies. In the control kidneys, we observed a very slight staining for TWEAK and Fn14 in glomeruli. By contrast, TWEAK and Fn14 were detected in glomerular crescents in the IgAN patients with crescents, which is consistent with the clinical relationship between UTWEAK and extracapillary proliferation. Although glomerular crescents are recognized as a heterogeneous composition of cells and matrix, recent evidence suggests the presence of podocytes in these structures [42-44]. The dedifferentiation of podocytes leads to podocyte proliferation within Bowman's space and the collapse of glomerular tufts [13]. Further proliferation of podocytes and parietal cells result in the formation of crescents [13,45]. Moreover, the potential contribution of proinflammatory cytokines and macrophages during the effector phase of crescentic GN has been indicated [46]. These findings, together with TWEAK-induced cell motility in podocytes and TWEAK and Fn14 expression in crescents of IgAN suggest that TWEAK/Fn14 may be involved in the podocyte alterations and subsequent crescent formation.

The present study showed that the levels of UTWEAK in IgAN patients significantly decreased according to the treatment responses. Urinary biomarkers are attractive candidates for accurately reflecting the activity of kidney injury. Our findings indicate that UTWEAK may be useful as a biomarker to predict the histologic findings, especially crescent formation and disease activity in IgAN.

Although we could not identify which cells are responsible for the TWEAK production, our results indicate that TWEAK locally production and the subsequent inflammatory responses may be involved in podocytes, mesangial cells, and infiltration of macrophages in the kidney. It appears that there are different causes of increased uTWEAK levels between the IgAN patients and the MCD patients. In the MCD patients, podocyte injuries and loss of GBM charge would result in the massive leakages of TWEAK, and probably be the main cause of the high levels of uTWEAK. On the other hand, the production of TWEAK in the IgAN patients may be associated with the leakages and injured glomerular cells such as podocytes and mesangial cells.

This study has several limitations. First, the levels of uTWEAK do not clearly distinguish the patient groups, there seems to be substantial overlap between IgAN and CKD. Second, a decrease in uTWEAK is shown in IgAN patients who receive steroid therapy, we were not able to analyze the changes of UTWEAK in those patients who did not receive immunosuppressive therapies because urine samples were not obtained. Finally, this study was performed only in Juntendo University Hospital, and the number of patients was small. Further studies are required to elucidate the mechanisms underlying TWEAK/Fn14 signaling and its role in pathophysiology of patients with IgAN.

\section{Conclusion}

In conclusion, the relationship between the levels of uTWEAK and clinicopathological findings observed in this study suggests that TWEAK/Fn14 system affects crescent formation and proteinuria in patients with IgAN.

\section{Abbreviations}

TWEAK: TNF-like weak inducer of apoptosis; Fn14: Fibroblast growth factor-inducible-14; uTWEAK: Urinary TWEAK; CKD: Chronic kidney disease; IgAN: IgA nephropathy; ESRD: End-stage renal disease; GBM: Glomerular basement membrane; MCP-1: Monocyte chemoattractant protein-1; IL: Interleukin; MCD: Minimal change disease; MN: Membranous nephropathy; LN: Lupus nephritis; FSGS: Focal segmental glomerulosclerosis; CR: Clinical remission; PR: Partial remission; sTWEAK: Serum TWEAK; ELISA: Enzyme-linked immunosorbent assay; eGFR: Estimated glomerular filtration rate;

IQR: Interquartile range; ANOVA: Analysis of variance; GN: Glomerulonephritis; NF-kB: Nuclear factor-kB.

\section{Competing interests}

The authors declare that they have no competing interests.

\section{Authors' contributions}

YS, YS, YS, YT conceived and designed the study. YS, YS performed the experiments, and analyzed the data. SH helped in conducting the study. YS, YS, YS drafted the manuscript. All authors read and approved the final manuscript.

\section{Acknowledgements}

We thank Ms. Terumi Shibata and Ms. Tomomi Ikeda (Division of Molecular and Biochemical Research, Juntendo University Graduate School of Medicine) for their excellent technical assistance. We also acknowledge the technical assistance and advice of Yuko Kojima, PhD (Laboratory of morphology and image analysis, Biomedical research center, Juntendo University Graduate School of Medicine). This study was supported in part by research funds from a Grant-in-Aid for Progressive Renal Disease Research, Research on Intractable Diseases, from the Ministry of Health, Labor, and Welfare of Japan and a grant from the Study Group on IgA Nephropathy in Japan.

Received: 14 November 2014 Accepted: 20 February 2015

Published online: 14 March 2015 


\section{References}

1. Chicheportiche Y, Bourdon PR, Xu H, Hsu YM, Scott H, Hession C, et al. TWEAK, a new secreted ligand in the tumor necrosis factor family that weakly induces apoptosis. J Biol Chem. 1997;272:32401-10.

2. Winkles JA. The TWEAK-Fn14 cytokine-receptor axis: discovery, biology and therapeutic targeting. Nat Rev Drug Discov. 2008;7:411-25.

3. Wiley SR, Cassiano L, Lofton T, Davis-Smith T, Winkles JA, Lindner V, et al. A novel TNF receptor family member binds TWEAK and is implicated in angiogenesis. Immunity. 2001;15:837-46.

4. Feng SL, Guo Y, Factor VM, Thorgeirsson SS, Bell DW, Testa JR, et al. The Fn14 immediate-early response gene is induced during liver regeneration and highly expressed in both human and murine hepatocellular carcinomas. Am J Pathol. 2000;156:1253-61.

5. Sanz AB, Sanchez-Niño MD, Ortiz A. TWEAK, a multifunctional cytokine in kidney injury. Kidney Int. 2011;80:708-18.

6. Yilmaz MI, Carrero JJ, Ortiz A, Martin-Ventura JL, Sonmez A, Saglam M, et al. Soluble TWEAK plasma levels as a novel biomarker of endothelia function in patients with chronic kidney disease. Clin J Am Soc Nephrol. 2009:4:1716-23.

7. Carrero JJ, Ortiz A, Qureshi AR, Martin-Ventura JL, Barany P, Heimburger O, et al. Additive effects of soluble TWEAK and inflammation on mortality in hemodialysis patients. Clin J Am Soc Nephrol. 2009;4:110-8.

8. Schwartz N, Su L, Burkly LC, Mackay M, Aranow C, Kollaros M, et al. Urinary TWEAK and the activity of lupus nephritis. J Autoimmun. 2006;27:242-50.

9. Schwartz N, Rubinstein T, Burkly LC, Collins CE, Blanco I, Su L, et al. Urinary TWEAK as a biomarker of lupus nephritis: a multicenter cohort study. Arthritis Res Ther. 2009;11:R143.

10. D'Amico G. The commonest glomerulonephritis in the world: IgA nephropathy. Q J Med. 1987:64:709-27.

11. Nair R, Walker PD. Is IgA nephropathy the commonest primary glomerulopathy among young adults in the USA? Kidney Int 2006;69:1455-8.

12. Wyatt RJ, Julian BA. IgA nephropathy. N Engl J Med. 2013;368:2402-14

13. Greka A, Mundel P. Cell biology and pathology of podocytes. Annu Rev Physiol. 2012;74:299-323.

14. Asao R, Asanuma $K$, Kodama F, Akiba-Takagi M, Nagai-Hosoe $Y$, Seki T, et al. Relationships between levels of urinary podocalyxin, number of urinary podocytes, and histologic injury in adult patients with IgA nephropathy. Clin J Am Soc Nephrol. 2012;7:1385-93.

15. Lemley KV, Lafayette RA, Safai M, Derby G, Blouch K, Squarer A, et al. Podocytopenia and disease severity in IgA nephropathy. Kidney Int. 2002;61:1475-85.

16. Tomino Y. Pathogenesis of IgA nephropathy. Contrib Nephrol. 2007;157:1-7.

17. Justo P, Sanz AB, Sanchez-Nino MD, Winkles JA, Lorz C, Egido J, et al. Cytokine cooperation in renal tubular cell injury: the role of TWEAK. Kidney Int. 2006;70:1750-8.

18. Gao HX, Campbell SR, Burkly LC, Jakubowski A, Jarchum I, Banas B, et al. TNF-like weak inducer of apoptosis (TWEAK) induces inflammatory and proliferative effects in human kidney cells. Cytokine. 1997;46:24-35.

19. Sanz AB, Justo P, Sanchez-Nino MD, Blanco-Colio LM, Winkles JA, Kreztler M, et al. The cytokine TWEAK modulates renal tubulointerstitial inflammation. J Am Soc Nephrol. 2008;19:695-703.

20. Izquierdo MC, Sanz AB, Mezzano S, Blanco J, Carrasco S, Sanchez-Nino MD, et al. TWEAK (tumor necrosis factor-like weak inducer of apoptosis) activates CXCL16 expression during renal tubulointerstitial inflammation. Kidney Int. 2012;81:1098-107

21. Moreno JA, Izquierdo MC, Sanchez-Nino MD, Suarez-Alvarez B, Lopez-Larrea C, Jakubowski A, et al. The inflammatory cytokines TWEAK and TNFa reduce renal klotho expression through NFkB. J Am Soc Nephrol. 2011;22:1315-25.

22. Sanz AB, Izquierdo MC, Sanchez-Nino MD, Ucero AC, Egido J, Ruiz-Ortega M, et al. TWEAK and the progression of renal disease: clinical translation. Nephrol Dial Transplant. 2014:29:154-62.

23. Campbell S, Burkly LC, Gao HX, Berman JW, Su L, Browning B, et al. Proinflammatory effects of TWEAK/Fn14 interactions in glomerular mesangial cells. J Immunol. 2006;176:1889-98.

24. Cattran DC, Coppo R, Cook HT, Feehally J, Roberts IS, Troyanov S, et al. The Oxford classification of IgA nephropathy: rationale, clinicopathological correlations, and classification. Kidney Int. 2009;76:534-45.

25. Roberts IS, Cook HT, Troyanov S, Alpers CE, Amore A, Barratt J, et al. The Oxford classification of IgA nephropathy: pathology definitions, correlations, and reproducibility. Kidney Int. 2009;76:546-56.
26. Suzuki Y, Matsuzaki K, Suzuki H, Sakamoto N, Joh K, Kawamura T, et al. Proposal of remission criteria for IgA nephropathy. Clin Exp Nephrol. 2014;18:481-6.

27. Matsuo S, Imai E, Horio M, Yasuda Y, Tomita K, Nitta K, et al. Collaborators developing the Japanese equation for estimated GFR: revised equations for estimated GFR from serum creatinine in Japan. Am J Kidney Dis. 2009;53:982-92.

28. Kawamura $T$, Joh $K$, Okonogi $H$, Koike $K$, Utsunomiya $Y$, Miyazaki $Y$, et al. A histologic classification of IgA nephropathy for predicting long-term prognosis: emphasis on end-stage renal disease. J Nephrol. 2013;26:350-7.

29. Shankland SJ, Pippin JW, Reiser J, Mundel P. Podocytes in culture: past, present, and future. Kidney Int. 2007;72:26-36.

30. Asanuma K, Yanagida-Asanuma E, Faul C, Tomino Y, Kim K, Mundel P. Synaptopodin orchestrates actin organization and cell motility via regulation of RhoA signalling. Nat Cell Biol. 2006;8:485-91.

31. Hidaka T, Suzuki Y, Yamashita M, Shibata T, Tanaka Y, Horikoshi S, et al. Amelioration of crescentic glomerulonephritis by RhoA kinase inhibitor, Fasudil, through podocyte protection and prevention of leukocyte migration. Am J Pathol. 2008;172:603-14.

32. Ruiz-Ortega M, Ortiz A, Ramos AM, Ramos AM. Tumor necrosis factor-like weak inducer of apoptosis (TWEAK) and kidney disease. Curr Opin Nephro Hypertens. 2014;23:93-100

33. Sanchez-Nino MD, Poveda J, Sanz AB, Mezzano S, Carrasco S, Fernandez Fernandez B, et al. Fn14 in podocytes and proteinuric kidney disease. Biochim Biophys Acta. 1832;2013:2232-43.

34. Burt D, Salvidio G, Tarabra E, Barutta F, Pinach S, Dentelli P, et al. The monocyte chemoattractant protein-1/cognate CC chemokine receptor 2 system affects cell motility in cultured human podocytes. Am J Pathol. 2007;171:1789-99.

35. Lee EY, Chung CH, Khoury CC, Yeo TK, Pyagay PE, Wang A, et al. The monocyte chemoattractant protein-1/CCR2 loop, inducible by TGF-beta, increases podocyte motility and albumin permeability. Am J Physiol Renal Physiol. 2009:297:F85-94.

36. Tarabra E, Giunti S, Barutta F, Salvidio G, Burt D, Deferrari G, et al. Effect of the monocyte chemoattractant protein-1/CC chemokine receptor 2 system on nephrin expression in streptozotocin-treated mice and human cultured podocytes. Diabetes. 2009:58:2109-18.

37. Coppo R, Troyanov S, Bellur S, Cattran D, Cook HT, Feehally J, et al. Validation of the Oxford classification of IgA nephropathy in cohorts with different presentations and treatments. Kidney Int. 2014;86:828-36.

38. Herzenberg AM, Fogo AB, Reich HN, Troyanov S, Bavbek N, Massat AE, et al. Validation of the Oxford classification of IgA nephropathy. Kidney Int. 2011;80:310-7

39. Shi SF, Wang $S X$, Jiang $L$, LV JC, Liu $L$, Chen $Y Q$, et al. Pathologic predictors of renal outcome and therapeutic efficacy in IgA nephropathy: validation of the oxford classification. Clin J Am Soc Nephrol. 2011:6:2175-84.

40. EdströmHalling S, Söderberg MP, Berg UB. Predictors of outcome in paediatric IgA nephropathy with regard to clinical and histopathological variables (Oxford classification). Nephrol Dial Transplant. 2012;27:715-22.

41. Katafuchi R, Ninomiya T, Nagata M, Mitsuiki K, Hirakata H. Validation study of oxford classification of IgA nephropathy: the significance of extracapillary proliferation. Clin J Am Soc Nephrol. 2011;12:2806-13.

42. Bariety J, Bruneval P, Meyrier A, Mandet C, Hill G, Jacquot C. Podocyte involvement in human immune crescentic glomerulonephritis. Kidney Int. 2005:68:1109-19.

43. Thorner PS, Ho M, Eremina V, Sado Y, Quaggin S. Podocytes contribute to the formation of glomerular crescents. J Am Soc Nephrol. 2008;19:495-502.

44. Sistani $L$, Rodriguez PQ, Hultenby K, Uhlen M, Betsholtz C, Jalanko H. Neuronal proteins are novel components of podocyte major processes and their expression in glomerular crescents supports their role in crescent formation. Kidney Int. 2013:83:63-71.

45. Kriz W, LeHir M. Pathways to nephron loss starting from glomerular diseases-insights from animal models. Kidney Int. 2005;67:404-19.

46. Tipping PG, Holdsworth SR. T cells in crescentic glomerulonephritis. J Am Soc Nephrol. 2006;17:1253-63. 